If any single message is conveyed by this work it is that the mere existence of the immense plurality of opinion in this field actually denies the possibility of absolute truths. If any exception is seen it is the need to maintain the patient's autonomy of choice, based on sound information.

DAVID R BROMHAM Senior Lecturer and Honorary Consultant in Obstetrics and Gynaecology, Department of Obstetrics and Gynaecology,

St James's Hospital, Leeds

\section{Medical Law: Text and Materials}

Ian Kennedy and Andrew Grubb, 1224 pages, London, $£ 30.00$, Butterworths, 1989

Whether or not they have been entirely happy about the process, the courts have been required increasingly frequently to pronounce on matters touching on medical ethics. In decisions on a wide range of subjects, judges have been obliged to decide not just what the legal rule is, but what is the morally acceptable response to a particular problem. This has given rise to a body of jurisprudence which cannot be ignored by those with an interest in the subject. One could not, for example, discuss the British response to the issue of teenage access to contraception fully without a nod in the direction of the Gillick decision. Nor would a debate on attitudes in the United Kingdom to the sterilisation of the mentally handicapped be complete without some reference to the several decisions which the British courts have now handed down on this morally difficult matter.

In this weighty (over twelve hundred pages) collection of medico-legal materials, Ian Kennedy and Andrew Grubb have burrowed their way through a vast mountain of court decisions, legislation and legal commentary, to come up with a compilation of the legal response to both old and new medical problems. The value of this enterprise to the lawyer is self-evident, particularly in an area of the law which has spawned a notoriously large literature. But what is there here for the non-lawyer - for the broad constituency of those interested in medical ethics?

There is a great deal. From the very beginning of their exhaustive enterprise, the authors stress the interrelationship of law and ethics in this area. The law is seen as one way of resolving certain immediate uncertainties or disputes, but the ethical dimension of what might otherwise be mistaken for a narrow legal issue is not ignored. Then, in each of the topics subsequently addressed, ethical issues are raised and discussed. But this of itself is probably no reason for the book to be read by the reader interested in medical ethics; the ethical material excerpted is usually from familiar sources (the President's Commission, Beauchamp and Childress etc). The real attraction for such a reader will be the legal treatment itself. Many reports are difficult to get hold of, as may also be the case with statutes or the reports of government bodies. This book reproduces the relevant section of the judgements or the legislation, thus providing ready access to the essence of the legal problem.

This is particularly useful in relation to the American court decisions reproduced here. Although Kennedy and Grubb concentrate on English law, the decisions of other common law countries, including those of the United States, are quoted where appropriate. Thus, for example, there are reproduced here some of the more important American decisions on the cessation of treatment in hopeless cases, an area of the law on which there is very little British authority (apart from the decision in one or two cases involving the treatment of mentally handicapped children). For those interested in the problem of the excessive prolongation of life, the facts of these cases - and the legal response - give considerable flesh to an issue which might otherwise remain a theoretical debate.

There is now a reasonable choice of general textbooks on medico-legal issues available to the non-legal reader. This book takes this process further, in providing such a reader with direct and helpfully guided access to the raw materials of the legal debate. For this reason, it is of immense value and interest.

ALEXANDER MCCALL SMITH Senior Lecturer, Faculty of Law, University of Edinburgh

\section{The Misfortunes of Others: End-stage Renal Disease in the United Kingdom}

\author{
Thomas Halper, 219 pages, \\ Cambridge, $£ 25.00$, Cambridge \\ University Press, 1989.
}

I have experienced great difficulties in reviewing this book. This is partly because I am, as an economist, unclear why the book was written, or from what specific perspective, since nowhere is the author or his background described.

The book covers various considerations regarding end-stage renal disease in the United Kingdom. It presents in chapter 1 some useful comparative data concerning renal dialysis and transplantation in the UK vis-a-vis such activities in other countries. Chapter 2 deals with what is called 'macro allocation', essentially looking at resource allocation under the UK National Health Service; chapter 3 concerns 'micro allocation' ie decisionmaking with respect to resource allocation in the specific context of endstage renal disease; and the fourth and final chapter offers what are called 'some premature conclusions'.

Having agreed to review this book, I then found myself wading through too many platitudes, together with contradictory statements and nuances, never quite knowing where the author sought to lead me.

A couple of comments may exemplify why I am so unhappy with this book. On page 120 the author states apparently in some degree of horror or, at a minimum, distaste - 'a nephrologist who was interviewed volunteered that he and his colleagues prescribed lower dosages of some drugs in order to save money'. But so what? Why is saving money - which might be better used elsewhere - seemingly so wrong?

On page 117, the author states: 'It is true, of course, that treating only patients with the best prognoses is the most effective use of scarce resources; more patients per unit of resources can be treated in this way than by any alternative approach. Some observers might retort, however, that efficiency is not the highest value. Ought dialyzing ten Charles Mansons be preferred to dialyzing five Mozarts (or five of my saintly uncles) merely because the Mansons have better prognoses?'

There are several problems with this. First it is not the case that the statement 'treating only patients with the best 
prognoses is the most effective use of scarce resources' leads necessarily to the statement, as is implied, that 'more patients per unit of resources can be treated in this way than by any alternative approach'. Second, neither statement can be equated with efficiency (as is implied by the second sentence) and third, since efficiency is concerned with maximising social benefit from the available resources, then if society wishes to place a higher value on certain individuals or (more likely in the context of health care) on groups of individuals, then this will be and should be reflected in efficiency.

Such muddled thinking is but an example. The author seems not to understand the concept of efficiency nor to accept the notion of scarcity of resources. But since, as an economist, I accept both, I cannot recommend that readers of the JME devote their time-a scarce resource - to reading this book.

I have never before written such a negative review of a book. I hope I never have to again for it is not a pleasant experience.

PROFESSOR G MOONEY Institute for Social Medicine, Blegdamsvej 3, 2200 Copenhagen $N$, Denmark

\section{Surrogate Motherhood}

Martha A Field, 215 pages, London, £17.95, Harvard University Press, 1988.

In this readable yet scholarly book, Martha Field provides a welcome overview of the legal and 'human' aspects of surrogacy. In a compelling introduction she narrates vividly some of the real life conflicts which have arisen from surrogacy, culminating in the well-known case of Mary Beth Whitehead, who, after entering into a contract to act as a surrogate mother for William and Betsy Stern, refused to hand over the baby, after birth, to its biological father. The resulting conflict, which became known as the case of Baby M, brought surrogate motherhood to public attention in the USA and elsewhere.

The major part of the book consists of an examination of surrogacy and reflections on the law's response to it. Professor Field considers surrogacy in general and then looks in some detail at surrogacy contracts. Of its nature surrogate motherhood is impossible to ban effectively - indeed its very existence is hard to assess as it can be achieved without medical intervention. But contracts for surrogacy, which apparently emerged in the 1970 s, seem to raise new problems. How should society treat these contracts? The options available to a legislature are to ban all such contracts, making them illegal; to allow them but to make them completely or partially unenforceable by one or both parties; or to apply the usual principle of contract law and to enforce them accordingly.

The author examines considerations of public policy which might demand the outlawing of surrogacy and then analyses the true nature of surrogacy contracts. Are they contracts for sale? If so they must conflict with the legal provisions which prohibit baby-selling in most States of the Union. Are they contracts for services? If so it may be argued that they exploit women and commercialise child-bearing in an undesirable way - since they will usually involve the use of poorer, disadvantaged women by more privileged and affluent couples. A counterargument presented here is that legal prohibition of surrogacy would be unduly paternalistic since surrogacy can be and often is entered into freely - to the woman's advantage or for altruistic reasons.

An interesting feature of the book is the consideration of the constitutional aspects of surrogacy; does the US Constitution support the right to surrogacy through the 'right to procreate', through the fourteenth amendment, providing for 'equal protection', or through the application of the 'due process' clause to the notion of a man's right to have issue which is biologically his? Can the Constitution not be used to support the right of a surrogate mother not to be deprived of her child if she changes her mind and wishes to keep it? These arguments, though of varying effectiveness, are instructive, especially for public lawyers, but Martha Field concludes that they are unlikely to be helpful in the determination of surrogacy disputes.

She then examines the relevant factors which the courts may consider, apart from contract, in custody disputes between biological father and surrogate mother. The judgement of who is the 'better parent' is notoriously difficult and fraught, as the book ably demonstrates, with unconscious prejudices about life-styles and cultural norms - such as those demonstrated in the Baby $\mathbf{M}$ case, where Mary Beth Whitehead's fitness for motherhood? was judged and found to be inferior by predominantly middle-class judiciary? and professional witnesses.

In conclusion, the autho recommends that surrogacy contracts should not, on balance, be made illegal $\mathbb{D}$ but that they should be unenforceable against the surrogate mother if shes changes her mind; she can then keep the child, subject to returning paymentsreceived by her. In the absence of contractual considerations, the painfu? dilemmas of custody of the child should be resolved by adopting a number of clear rules - especially by a presumption that the 'primary caretaker' has a right' to the custody of the child - in the case of a newborn child usually the mother. Other rules, regulating visiting right and financial obligations, are also suggested, so as to minimise the suffering and doubt of all parties bup especially of the child.

These recommendations are clea $\frac{\mathbb{}}{\not}$ and the arguments leading to them wello made. Some minor quibbles remain: the chapter which considers the effecto $\overrightarrow{6}$ new reproductive techniques on the family falls somewhere between Jan adequate general discussion of the problems and a specific look at thos linked with surrogacy; nor does the book examine the situation which will presumably, occur increasingly - thछ mother's position where she provides as it were, merely a uterus in which \& fertilised ovum is implanted and contributes no genetic material to the child she bears. Finally although the book deals with the 'human' issues, the author does not perhaps do justice to the ethical grounds for objecting tơ surrogacy. Subject to these minof. criticisms, this book is an excellent and welcome addition to the literature on an important area of law and medicine.

MAUREEN MULHOLLANEO Lecturer in Law, Faculty of Law University of Manchester, Oxford RoadN Manchester M13 9PE

Faces of Medicine:
Philosophical Study

W J van der Steen and P J Thung, 236 pages, Dordrecht, $£ 38.00$, Kluwer Academic Publishers, 1988

This is an interesting book and ap unusual one. It is unusual, first, because although written from a 